http://dx.doi.org/10.11646/phytotaxa.76.3.11

\title{
Notes on Early Land Plants Today. 23. A new synonym in Anthoceros (Anthocerotaceae, Anthocerotophyta)
}

\author{
D. CHRISTINE CARGILL ${ }^{1}$, LARS SÖDERSTRÖM ${ }^{2,4}$, ANDERS HAGBORG $^{3} \&$ MATT VON KONRAT $^{3}$ \\ ${ }^{I}$ Centre for Australian National Biodiversity Research, Australian National Herbarium, GPO Box 1600, Canberra, ACT 2601, \\ Australia; chris.cargill@environment.gov.au \\ ${ }^{2}$ Department of Biology, Norwegian University of Science and Technology, N-7491 Trondheim, Norway; lars.soderstrom@bio.ntnu.no \\ ${ }^{3}$ Department of Botany, The Field Museum, 1400 South Lake Shore Drive, Chicago, IL 60605-2496, USA; hagborg@pobox.com, \\ mvonkonrat@fieldmuseum.org \\ ${ }^{4}$ Author for correspondence
}

Stephani (1916) described two species of Anthoceros Linnaeus (1753: 1139) from Queensland, Australia, but the application of these names has been unclear. Herbarium collections at B, BM, HBG, L, MEL, PC, and W were searched in an attempt to find original material of these taxa. Two packets were found at $G$ in the Stephani herbarium, one bearing the name Anthoceros fragilis (barcode G-61292) and the other lablled Anthoceros fertilis (barcode G-61293). Both annotations were in Stephani's handwriting and the specimens match the descriptions in the protologue.

The first author studied the G specimens and found they represent to the same taxon. Since the two names have equal priority, Anthoceros fragilis was chosen over Anthoceros fertilis, as the epithet more accurately describes the thallus, which is thinner and more delicate than that in the type species for the genus, Anthoceros punctatus Linnaeus (1753: 1139).

Both specimens at $\mathrm{G}$ were collected by Amalie Dietrich from the Brisbane River area in Queensland. Dietrich's herbarium is now in HBG with duplicates in many other herbaria. However, no duplicates of the Anthoceros material were found in HBG or several other herbaria with significant holdings of Dietrich specimens. Stephani based his descriptions of Anthoceros fragilis and Anthoceros fertilis on the specimens held in G, which appears to be the only extant type material for these names. They are thus regarded here as holotypes, despite an annotation by Proskauer on the specimen of Anthoceros fertilis to indicate that it was an isotype.

\section{Formal treatment}

The format of this note follows Söderström et al. (2012).

Anthoceros fragilis Steph., Sp. Hepat. (Stephani) 5: 1006, 1916 (Stephani 1916).

Type:-AUSTRALIA. Queensland: Amalie Dietrich (holotype G-61292! [=G-24322! $]^{1}$ ).

= Anthoceros fertilis Steph., Sp. Hepat. (Stephani) 5: 1006, 1916 (Stephani 1916), syn. nov. Type:-AUSTRALIA. Eastern Queensland: Brisbane River. 1865, Amalie Dietrich 804 (holotype G-61293! [=G-24321!]).

1. Citation of specimens in G should preferably use the barcode (M. Price, pers. comm.) but for comparability the numbers printed on the specimen, which have often been cited by previous authors, are also given here in square brackets. 


\section{Acknowledgement}

We thank Gerhard Thijsse (L), Tassilo Feuerer (HBG), Len Ellis (BM), H.J.M. Sipman (B), Rob Gradstein (PC), Anton Igersheim (W) and Pina Milne (MEL) for help with tracing possible type material. Also many thanks to Anna Monro for advice.

\section{References}

Linnaeus, C. (1753) Species Plantarum, ed. 1. Impensus Laurentii Salvii, Holmiae [Stockholm], 1200 pp.

Söderström, L. Hagborg, A. \& von Konrat, M. (2012) Notes on Early Land Plants Today. Phytotaxa 65: 41-42.

Stephani, F. (1916) Species Hepaticarum 5. George \& Cie, Genève \& Bale, pp. 849-1008. 